\title{
O erotismo em Manuel Bandeira: o limite das palavras e a revelação pelo ocultamento
}

\author{
Norberto Perkoski (Universidade de Santa Cruz do Sul - UNISC)
}

\begin{abstract}
RESUMO: Este trabalho aborda a poética erótica de Manuel Bandeira, revelando a predominância de uma escritura transgressora pelo ocultamento. A linguagem tende, por um lado, a amenizar o que dito de outra forma pareceria grosseiro e, por outro, busca atingir a ultrapassagem sígnica para melhor desvelar o êxtase da paixão e a dificuldade de expressá-la, resultando o paradoxo que une excesso e falência. Como Eros apresenta várias faces, Manuel Bandeira não foge a nenhuma delas, focalizando-as através de uma escritura que ora aparece vestida, ora cintila a sua nudez, ora esconde para melhor entrever a força deslocadora que a sensualidade impõe ao humano.
\end{abstract}

PALAVRAS-CHAVE: poesia, erotismo, escritura erótica, Manuel Bandeira.

\begin{abstract}
This paper broaches the erotic poetry of Manuel Bandeira, unveiling the prevalence of a transgressive writing through its concealment. The language tends, on the one hand, to mitigate what otherwise might sound rude, while, on the other hand, it seeks to attain the signic trespassing able to depict passion's extasy and the difficulty to express it, thus resulting in the paradox which fuses excess and failure. Given that Eros is multifaceted, Manuel Bandeira does not evade any of those faces, by portraying them through a writing both dressed and nude and sometimes hidden to better depict the dislocating strength which sensuality imposes to mankind.
\end{abstract}

KEYWORDS: poetry, eroticism, erotic writing, Manuel Bandeira.

Considerado pela crítica como a obra em que Manuel Bandeira ${ }^{1}$ atinge o seu momento de maturidade dentro da proposta modernista, que se vinha ensaiando nas obras anteriores,Libertinagem (1930) apresenta poemas eróticos que incorporam plenamente o verso livre e a liberdade de linguagem, no que tange ao aspecto formal, e a simplicidade do cotidiano, no que se refere ao plano conteudístico. Esses elementos também se farão presentes nas obras seguintes sem que, entretanto, o poeta abdique de alguns dos motivos eróticos já trabalhados nas anteriores, ou, melhor dizendo, o poeta assimila essas conquistas e incorpora-as também à temática que se associa ao amor, ao erotismo 
e à constelação que a envolve. Davi Arriguci Jr. ressalta que, em Libertinagem, Manuel Bandeira une "ostensivamente transgressão formal e erotismo" (1990, p. 163).

O poema de abertura "Não sei dançar" retoma o motivo de "Sonho de uma terça-feira gorda" deCarnaval (1919), só que agora não mais em nível onírico, e, sim, de realidade ("Eis por que vim assistir a este baile de terça-feira gorda"), uma vez que o eu-poético tenta integrar-se na folia:

Uns tomam éter, outros cocaína.

Eu já tomei tristeza, hoje tomo alegria.

Tenho todos os motivos menos um de ser triste. (p. 93)

O verso final da citação anterior, pleno de auto-ironia, será retrabalhado e explicitamente esclarecido na segunda estrofe, na qual elementos autobiográficos são usados como matéria poética:

Sim, já perdi pai, mãe, irmãos.

Perdi a saúde também.

É por isso que sinto como ninguém o ritmo do jazz-band.

A categoria de Bakhtin (1981) da livre integração entre os homens no período carnavalesco se faz presente internamente no poema, pois uma arrumadeira dança com o ex-prefeito municipal e também um japonês - "a fração incipiente amarela" - participa da festa, e o eu-lírico não deixa, de certa forma, de se enternecer com essa amálgama racial: "De fato este salão de sangues misturados parece o Brasil..."

Os elementos eróticos aparecem representados na avaliação sensual e competitiva entre duas figuras femininas:

\footnotetext{
A filha do usineiro de Campos

Olha com repugnância

Para a crioula imoral.

No entanto o que faz a indecência da outra

É dengue nos olhos maravilhosos da moça.

E aquele cair de ombros...
}

Mas ela não sabe...

Tão Brasil! (p. 93-94)

A estrofe final abre com um verso em que a intromissão racional do eu-lírico tenta, momentaneamente, solapar a pretensão de participação festiva: "Ninguém se lembra da política..." O fecho reticencial desdobra-se, no entanto, em duas direções: a percepção 
do caráter alienante do carnaval e, por outro lado, a aceitação resignada de que não só de conscientização se faz a vivência humana. Na sequiência poemática, depois de salientar a grandeza territorial do Brasil e a primazia da qualidade do algodão do Seridó, o eu-lírico abandona essas preocupações racionalistas: "Que me importa?". Inclusive as doenças (a do próprio poeta implicitamente incluída), arroladas nos versos finais, são como se fossem igualmente catapultadas da festa:

Não há malária nem moléstia de Chagas nem ancilóstomos.

A sereia sibila e o ganzá do jazz-band batuca.

Eu tomo alegria!

Em "Na boca", outro poema que focaliza o tempo transgressor do carnaval, a primeira estrofe evidencia a tristeza e a impotência existencial:

Sempre tristíssimas estas cantigas de carnaval

Paixão

Ciúme

Dor daquilo que não se pode dizer (p. 113)

Contudo, novamente se insere a compreensão da necessidade da alienação, embora o eu-lírico não consiga atingi-la e passe a projetá-la na inveja de quem se joga integralmente nela. Comprove-se:

Felizmente existe o álcool na vida

E nos três dias de carnaval éter de lança-perfume

Quem me dera ser como o rapaz desvairado!

$\mathrm{O}$ ano passado ele parava diante das mulheres bonitas

E gritava pedindo o esguicho de cloretilo:

- Na boca! Na boca!

Umas davam-lhe as costas com repugnância

Outras porém faziam-lhe a vontade.

O desvario do rapaz encontrará eco nas pretensões mais recônditas do eu-lírico, em que o erótico se sobressai por detrás do "desejo incontentado" (ver em A cinza das horas, o poema "Tu que me deste o teu cuidado...", p. 35-36):

Ainda existem mulheres bastante puras para fazer vontade aos viciados

Dorinha meu amor...

Se ela fosse bastante pura eu iria agora gritar-lhe como o [outro:

- Na boca! Na boca! 
Predominantemente, o erotismo corporal em Manuel Bandeira, em função da tuberculose como componente impeditivo, evade-se ou para o imaginário, de que "Voume embora pra Pasárgada" (p. 117-118) é um exemplo significativo, tanto que nesse espaço utópico o poeta terá as mulheres que quiser, ou busca na infância os seus correlatos de espanto, encantamento e ternura. Para esse segundo caso, comprove-se com os seguintes excertos de "Evocação do Recife":

Um dia eu vi uma moça nuinha no banho

Fiquei parado o coração batendo

Ela se riu

Foi o meu primeiro alumbramento

$[\ldots]$

Eu me deitei no colo da menina e ela começou a passar a [mão nos meus cabelos (p. 106)

O encantamento infantil, enquanto evasão erótica, é tema também de "Porquinho-daíndia" (p. 100), no qual o eu-lírico afirma que o bichinho foi a sua primeira namorada. É importante elucidar que esse poema faz parte de um tríptico intratextual, sendo "Teresa" e "Madrigal tão engraçadinho" os outros dois. ${ }^{2}$

O segundo dos poemas da tríade ("Teresa") interessa de modo particular, porquanto trabalha poeticamente a noção de o ser perder-se de maneira completa quando envolvido pelo erótico.

Um outro dado que se torna interessante salientar é o fato de o poema também fazer uso da intertextualidade, estabelecendo um canto paralelo com "O 'adeus' de Teresa", criação lírica de Castro Alves, utilizando-se, de certa forma, da técnica composicional do poeta baiano, no entanto, alterando-lhe o processo seqüencial.

No poema de Castro Alves, o envolvimento do par amoroso ocorre através de três fases que se poderiam denominar de encontro comprometido, relação sexual, separação problemática. Em Manuel Bandeira o processo é diverso: negação do corpo, negação da alma através do corpo e relação sexual. Veja-se o poema deste último:

\section{TERESA}

A primeira vez que vi Teresa

Achei que ela tinha pernas estúpidas 
Achei também que a cara parecia uma perna

Quando vi Teresa de novo

Achei que os olhos eram muito mais velhos que o resto do corpo

(Os olhos nasceram e ficaram dez anos esperando que o resto do

[corpo nascesse)

Da terceira vez não vi mais nada

Os céus se misturaram com a terra

E o espírito de Deus voltou a se mover sobre a face das águas.

(p. 107-108)

Muitas vezes, o deslocamento que o desejo provoca, quando ainda inconsciente, é o da negação do objeto. Pelo temor de sucumbir ao que lhe é estranho em termos de racionalidade, ao que o ultrapassa conscientemente, o ser, num revés defensivo, procura destruir as qualidades daquilo que o atrai intensamente. É o que acontece no poema em pauta.

As duas primeiras estrofes exibem a negação do corpo do Outro, com uma diferença entre elas. Na primeira, o que é negado são as "pernas estúpidas". Note-se a escolha do adjetivo, que indica uma qualidade de caráter abstrato, atribuído à concretude de uma parte corporal à qual costumeiramente não vem associado. $\mathrm{O}$ temor, como se fosse um ato falho, trai o eu-lírico pelo deslocamento do termo, revelando, por um duplo viés, agressividade e ignorância. Quando, no último verso, o eu-lírico associa a cara à perna, transfere a sua avaliação e expõe, de forma mais evidente ainda, o seu receio.

A negação temerosa atinge o seu ápice na segunda estrofe através da consideração do olhar. A sabedoria popular, valendo-se do desgastado provérbio de que "os olhos são o espelho da alma", patenteia, aqui, uma verdade. O tom sarcástico, desmerecedor, do eulírico em relação ao Outro, é destruído pela "velhice" dos olhos, conotadora que é, no poema, de vivência antecipada, sabedoria, compreensão.

$\mathrm{Na}$ terceira estrofe, o eu-lírico sucumbe integralmente ao olhar do Outro, ambos fundindo-se em uma unidade, tornada evidente através do verbo reflexivo recíproco "se misturaram", que envolve tanto o sujeito quanto o objeto, sem distingui-los ou separálos.

"Madrigal tão engraçadinho", o terceiro poema da série, complementa o enleio encantatório pela figura feminina. O eu-lírico retoma do mundo mágico e feliz da 
infância a imagem do seu primeiro fascínio. A estranheza inicial da comparação (cf. também o poema "Namorados", p. 116) transmuta-se num galanteio sedutor, quando se tem em mente os outros dois poemas da tríade:

\section{MADRIGAL TÃO ENGRAÇADINHO}

Teresa, você é a coisa mais bonita que eu vi até hoje na minha vida, inclusive o porquinho-da-índia que me deram quando em tinha seis anos. (p. 112)

O clima surreal e a entrega plena que encerra o poema "Teresa" também se faz presente no poema inaugural e homônimo da obra Estrela da manhã (1936), no qual o eu-lírico num tom exacerbado no todo da composição e iniciando pela manifestação do desejo e da perda do objeto desejado ("Eu quero a estrela da manhã"; "Ela desapareceu ia nua") manifesta a sua intenção de comprometimento, mesmo que "a estrela da manhã" tenha se relacionado com vários tipos de homens:

Virgem mal-sexuada Atribuladora dos aflitos Girafa de duas cabeças Pecai por todos pecai com todos

Pecai com os malandros

Pecai com os sargentos

Pecai com os fuzileiros navais

Pecai de todas as maneiras

Com os gregos e os troianos

Com o padre e com o sacristão

Com o leproso de Pouso Alto

Depois comigo (p. 120)

Partindo-se da interpretação de que a "estrela da manhã" é a transfiguração da mulher, de certa forma idealizada pela própria abjeção, o eu-lírico propõe-se a aceitá-la integralmente, numa doação ilimitada:

Procurem por toda parte

Pura ou degradada até a última baixeza

Eu quero a estrela da manhã. (p. 121)

Cabe notar a ausência de pontuação - exceção feita às interrogações e ao ponto final do todo do poema -, expondo a intensidade do envolvimento do eu-lírico. Esse sentimento deslocador, em que, como já se viu, não estão ausentes as manifestações de erotismo 
intenso, encontra o seu correlato também na torrencialidade com que se apresenta o enunciado, abolindo as suas pausas. $\underline{3}$

Igualmente em "Balada das três mulheres do sabonete Araxá" (p. 122), o tom enfático é o mesmo, no entanto o objetivo diverge, insinuando uma situação cômica de envolvimento erotizado com as mulheres constantes em um invólucro de um produto de higiene. ${ }^{4}$

Já em Lira dos cinqüent'anos (1940) Manuel Bandeira elabora, no poema "Água-forte", uma obra-prima no que tange à escritura erótica transgressora pelo ocultamento. Em $O$ preto no branco(1955), Ledo Ivo, através da elucidação das metáforas que compõem o poema, desnuda o caráter de um assunto interdito, trabalhado poeticamente. A linguagem oculta é desvelada por meio de uma exegese crítica que, ao cabo, revela que o poema aborda "um sexo feminino em funcionamento menstrual". $\frac{5}{}$ Veja-se o poema:

\section{ÁGUA-FORTE}

O preto no branco,

O pente na pele:

Pássaro espalmado

No céu quase branco.

Em meio do pente,

A concha bivalve

Num mar de escarlata.

Concha, rosa ou tâmara?

No escuro recesso,

As fontes da vida

A sangrar inúteis

Por duas feridas.

Tudo bem oculto

Sob as aparências

Da água-forte simples:

De face, de flanco,

O preto no branco. (p. 147-148)

Na "tradução" das metáforas, o exegeta correlaciona "pente" ao púbis; "concha bivalve", aos pequenos lábios genitais; "o mar de escarlata", ao fluxo menstrual; "as fontes da vida", aos ovários. ${ }^{6}$ Salienta, avaliativamente, o crítico: 
Focalizou o poeta um desses assuntos proibidos, sobre os quais a criação artística costuma silenciar, por pudor, conveniência e talvez por um sentimento de repulsa, calando a evidência de um espetáculo que a alguns poderia parecer uma das misérias ou maldições da condição feminina, embora seja, simplesmente, uma exibição da sabedoria da natureza. (IVO, 1955, p. 52)

Acrescenta, ainda, que Manuel Bandeira "ousou atravessar a fronteira do silêncio estabelecido em torno de uma fronteira biológica" para celebrá-la através de um "idioma cifrado, de um código lírico em que a verdade se escondesse para melhor evidenciar-se" (IVO, 1955, p. 52).

Em "Unidade", por exemplo, poema constante da obra Belo belo (1948), Bandeira valese de elementos sacros para velar a intensidade do erotismo corporal, numa síntese dialética, como se verá na análise que segue:

\section{UNIDADE}

Minh'alma estava naquele instante

Fora de mim longe muito longe

Chegaste

E desde logo foi verão

O verão com as suas palmas os seus mormaços os seus [entos de sôfrega mocidade

Debalde os teus afagos insinuavam quebranto e molície

O instinto de penetração já despertado

Era como uma seta de fogo

Foi então que minh'alma veio vindo

Veio vindo de muito longe

Veio vindo

Para de súbito entrar-me violenta e sacudir-me todo

No momento fugaz da unidade. (p. 184-185)

O efeito de estranhamento desse poema advém de que a civilização cristã ocidental busca atingir a transcendência pela negação do corpóreo. Através do amortecimento dos sentidos, o objetivo projetado é a anulação das sensações, entre elas, primordialmente, as vinculadas à sexualidade, com a finalidade de alcançar, através de uma revelação epifânica, a integração com o sagrado. 
Manuel Bandeira subverte o processo. Não nega o corpo, mas parte dele para alcançar a transcendência através da relação sexual. A oposição entre continuidade $\mathrm{x}$ descontinuidade, categorias caras a Georges Bataille, em sua obra O erotismo, de 1957, desdobra-se, aqui, em dois níveis: na relação do ser consigo mesmo, isto é, na separação alma/corpo; e na ligação do ser com o diferente, uma vez que o Outro é sempre o dessemelhante. A unidade - na expressão sinônima de Bataille, "a continuidade perdida" - é passível de ser reencontrada na síntese dialética que incorpora o elemento sacro corpo e alma unificam-se - quando da integração com o Outro, através do perder-se no instante do gozo. Nada assegura, contudo, o conhecimento, nem do ser, uma vez que a consciência some nesse momento de plena intensidade, nem do Outro, pois nada garante que o Outro tenha auferido a mesma plenitude.

Reitera-se que, através da escritura erótica, Manuel Bandeira, como já foi salientado por Ledo Ivo, esconde para melhor desvelar. Os elementos de seleção formal aumentam, no texto em pauta, a densidade poemática. No dístico inicial, as vogais abertas iniciais ("alma"; "fora") parecem diluir-se nas nasalizações finais ("instante"; "longe"), distendendo os versos e alcançando, com esse recurso, o reforço do distanciamento alma $\mathrm{x}$ corpo.

Na segunda estrofe, com o aparecimento do Outro, deflagrador do desejo do eu-lírico, esse passa também a situar-se no tempo do desejo e da paixão imperiosa. A escolha da estação - "verão" - associa-se, pelos vocábulos eleitos como conexos ao seu campo semântico ("mormaços", "ventos de sôfrega mocidade"), à exacerbação do lado impulsivo do ser humano e, no caso específico do poema, envolve o instintivo masculino. Em contraponto tem-se a insinuação, a ondulação do Outro, pretendendo a distensão temporal, apropriadamente representada pelas nasalizações em "insinuavam" (também pelo hiato entre o "u" e o "a") e "quebranto" e pela ditongação final de "molície", que alongam o final do verso. No entanto, o tempo vencedor é o do eu-lírico e não o do Outro. A virilidade masculina suplanta a tentativa outra de prolongamento das sensações táteis. No início do verso seguinte, as vogais nasais sugerem o gradual enrijecimento do membro masculino ("o instinto de penetração") a que o eu-lírico não poderá fugir e que é reforçado pelas tônicas abertas finais ("já despertado"). A reação 
masculina aos carinhos encontra, na comparação de "seta de fogo" para o membro duro, ereto, uma resposta física imediata para a urgência da posse.

A aliteração em "veio vindo", repetida com propriedade três vezes, nos três primeiros versos da estrofe seguinte, acrescida novamente das nasalizações da própria palavra "vindo" e também de "longe", sugerem um aproximar-se gradativo e representam igualmente, na leitura proposta aqui, os movimentos masculinos da cadência rítmica de entrada e retirada do membro, do vaivém do coito. Os dois últimos versos indicam a ejaculação no nível físico e o momento final da síntese dialética unificadora do corpo e da alma, nesse instante integrados plenamente. A eleição da palavra "sacudir-me" reforça, através do significante a idéia veiculada pelo significado: a sibilante inicial, acrescida da estridência do "i" e do tremulante "r" podem ser associadas à intensidade do orgasmo masculino. O pronome "me" que se incorpora aos dois verbos ("entrar-me" e "sacudir-me") aponta para a invasão que sofre o sujeito no momento da plenitude do gozo.

No último verso, o adjetivo "fugaz" diz da impossibilidade de continuidade desse instante que é, por natureza, efêmero. O ser é, em si e para si, descontínuo. Esse "em si" deve ser entendido associando-o à dicotomia alma x corpo e o "para si" como a impossibilidade de integrar-se indefinidamente com o Outro.

O poema trabalha uma visão masculina da urgência do desejo e a figura do Outro surge, explicitamente, apenas para sugerir a extensão do tempo do desejo que - torna-se evidente pelo conteúdo poemático - não é atendido.

O próximo poema, estrategicamente colocado a seguir na disposição interna da obra, vincula-se com o precedente. Constate-se:

\section{ARTE DE AMAR}

Se queres sentir a felicidade de amar, esquece a tua alma.

A alma é que estraga o amor.

Só em Deus ela pode encontrar satisfação.

Não noutra alma.

Só em Deus - ou fora do mundo.

As almas são incomunicáveis. 
Deixa o teu corpo entender-se com outro corpo.

Porque os corpos se entendem, mas as almas não. (p. 185)

Só em momentos muito raros o ser consegue, momentaneamente, integrar-se com aquilo que o transcende e, mesmo assim, esse instante esvai-se tão logo a racionalidade invade o processo de pensamento. Daí por que em "Unidade" Manuel Bandeira faz uso da palavra "fugaz". Acrescido da vivência da impossibilidade da continuidade de fusão com o que o ultraprassa, em "Arte de amar" o poeta opta pela via do corpo, negando igualmente a integração continuada entre dois seres distintos no que tange à transcendência.

A vivência do inefável é intraduzível para o código da linguagem comum, cotidiana, pois essa centra-se na função referencial. Na tentativa de comunicar, aqueles que passam por tal experiência inventam uma linguagem outra que, ao final, se torna hermética, pois não encontra signos apropriados no código estabelecido. Além disso, essa experiência não se processa quando o ser almeja e sim em momentos singulares.

Como é impossível de comunicar o "momento fugaz" de que trata o poema "Unidade", uma vez que ele está associado à alma, ao mistério, resta, assim, tão-somente o corpo que, como trabalha Manuel Bandeira em "Arte de amar", pode chegar a um instante de participação no mistério, embora o mistério continue incognoscível.

Em alguns momentos, a linguagem de Manuel Bandeira tangencia a escritura transgressora pelo excesso, como, por exemplo, no poema "Infância", que fecha a obra Belo belo, no qual, relembrando as suas mais remotas experiências existenciais, não omite a que se refere à descoberta deslocadora do erotismo:

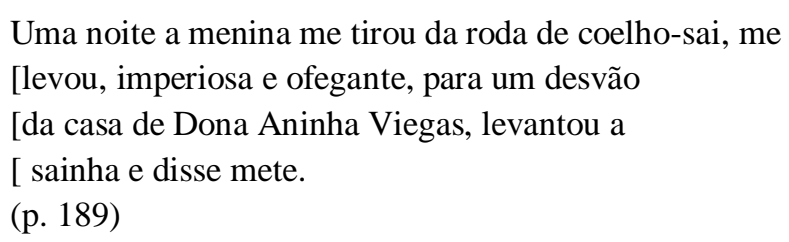

Yudith Rosenbaum assim se refere a essa passagem: 
No poema "Infância", a atitude decidida da menina ressalta em meio à passividade assustada do garoto. Todos os verbos referem-se a ela, cabendo a ele apenas cumprir a ordem imperativa: "mete". A carga maior concentra-se toda neste verbo, cujo tom ordenativo finaliza o verso, deixando ausente do poema a cena explícita. (1993, p. 68)

Resta salientar que, se no conjunto de sua obra, Manuel Bandeira elabora, predominantemente, uma escritura erótica insinuadora, em determinados poemas ocorre a tensão entre o erotismo evidenciado e o erotismo oculto, pois uma vez desvelado o que se esconde, expõem-se tanto a temática do interdito quanto a intensidade das imagens eleitas. Veja-se, como exemplo do que foi por último afirmado, o poema que segue, constante de Opus 10 (1950), em que se elege como intertexto um livro bíblico:

\section{CÂNTICO DOS CÂNTICOS}

- Quem me busca a esta hora tardia?

- Alguém que treme de desejo.

- Sou teu vale, zéfiro, e aguardo

Teu hálito... A noite é tão fria!

- Meu hálito não, meu bafejo,

Meu calor, meu túrgido dardo.

- Quando por mais assegurada

Contra os golpes de Amor me tinha,

Eis que irrompes por mim deiscente...

- Cântico! Púrpura! Alvorada!

- Eis que me entras profundamente

Como um deus em sua morada!

- Como a espada em sua bainha. (p. 203-204)

Subvertendo o texto original que se manifesta pleno da ternura e do cuidado de Salomão para com a rainha de Sabá, o eu-lírico do poema em foco manifesta a sua urgência através de uma linguagem agressiva. Frente ao enunciado feminino que busca imagens brandas e evanescentes para o seu desejo, contrapõem-se as falas masculinas que, uma vez decodificadas e associadas ao todo poemático, se revelam como transgressoras pelo excesso, marcadas que são pela intensidade ("Alguém que treme de desejo") e representadas pela ostensividade tanto de "bafejo", que se pode considerar como uma palavra agressiva, quanto de símbolos fálicos hostis, tais como "túrgido dardo" e "espada". 
Por fim, é pertinente reiterar que, na poética erótica de Manuel Bandeira, a linguagem tende, por um lado, a amenizar o que dito de outra forma poderia parecer grosseiro e, por outro, busca atingir a ultrapassagem dos signos lingüísticos para melhor revelar o êxtase da paixão e do gozo e a dificuldade de expressá-los em palavras, resultando, dessa forma, o paradoxo de uma linguagem que une excesso e falência.

Este estudo analítico ressalta, ao seu término, a invasão criativa que o poeta faz da temática do proibido. Na eleição dos temas e na intensidade com que são tratados, evidenciam-se formas de transgredir o interdito: uma que se oculta para melhor revelar, como em "Água-forte"; outra que tensiona a escritura em suavidade e agressividade, como em "Cântico dos cânticos".

Como Eros não se deixa aprisionar e apresenta inúmeras faces que vão desde o olhar extasiado, passando pela carícia amena até o desejo premente e agressivo, Manuel Bandeira não foge a nenhum desses disfarces, focalizando-os através de uma escritura que ora aparece vestida, ora cintila a sua nudez, ora esconde para melhor revelar a força deslocadora que a sensualidade impõe ao humano.

\section{NOTAS}

${ }^{1}$ Todas as citações do poeta serão extraídas da obra Estrela da vida inteira: poesias reunidas, 8. ed., Rio de Janeiro: J. Olympio, 1980, podendo ser confrontadas através das páginas colocadas entre parênteses no decorrer do trabalho. Cumpre esclarecer que este texto teve por base um dos capítulos de nossa tese de doutorado "A escritura erótica no sistema literário brasileiro", defendida em 1996, na PUCRS.

${ }^{2} \mathrm{Na}$ Revista do GT de Teoria do Texto Poético no 4, de 2007, no artigo "Fragmentos de uma subjetividade poética: três poemas de amor de Libertinagem, de Manuel Bandeira, Wilson José Flores Jr. também focaliza os textos em pauta. Disponível em: http://www.textopoetico.org

${ }^{3}$ Franklin de Oliveira apresenta uma interpretação semelhante:

Uma das características formais do poema é a ausência quase completa de pontuação. O apelo a esse recurso não obedece apenas a uma necessidade rítmica: é uma imposição de ordem psicológica. Eliminando a virgulação no verso patético, o poeta torna ainda mais impraticável a discriminação entre amigos e inimigos. A todos transmite um apelo patético: o de sua angústia. 
Cf. OLIVEIRA, Franklin de. O medievalismo de Bandeira: a eterna elegia. In: BRAYNER, Sônia (Org.). Manuel Bandeira. Rio de Janeiro: Civilização Brasileira; Brasília: Instituto Nacional do Livro, 1980. p. 256.

${ }^{4}$ Partindo de algumas pistas fornecidas pelo próprio poeta, Sônia Brayner realiza a análise desse poema, apontando os elementos intertextuais nele existentes. Cf. "O 'humour' bandeiriano ou as histórias de um sabonete". In: LOPEZ, Telê Porto Ancona. (Org.). Manuel Bandeira: verso e reverso. São Paulo: T. A. Queiroz, 1987. p. 42-47.

${ }^{5}$ IVO, Ledo. O preto no branco: exegese de um poema de Manuel Bandeira. Rio de Janeiro: São José, 1955. p. 47. Salienta-se que o poema em pauta já recebeu interpretação distinta da que se verá no corpo do texto. Para Leônidas Câmara, o poema focaliza "o misticismo do poeta [...] embora esbatido numa figuração de repetidas imagens plásticas interiorizadas". Acrescenta, ainda, o crítico:

em "Água-forte" tudo se reduz, afinal, à situação de início esboçada. A disposição dos objetos, sua escala cromática, o preto, o branco, o mar de escarlate, o céu quase todo branco, enfim, água-forte simples, todo esse jogo de contrastes, de imagens alternadas, duas a duas, contribui para formar o quadro sugerido mais pelas concepções abstratas do poeta que pela plana sensibilidade.

Cf. o artigo "A poesia de Manuel Bandeira: seu revestimento ideológico e formal". In: BRAYNER, Sônia (Org.). Manuel Bandeira. Rio de Janeiro: Civilização Brasileira; Brasília: Instituto Nacional do Livro, 1980. p. 173.

${ }^{6}$ Cf. a obra de Ledo Ivo, referenciada na nota 5, respectivamente as páginas 39, 49, 50 e 51.

\section{OBRAS CITADAS}

ARRIGUCCI JR., Davi. Humildade, paixão e morte: a poesia de Manuel Bandeira. São Paulo: Companhia das Letras, 1990.

BAKHTIN, Mikhail. Problemas da poética de Dostoiévski. Tradução de Paulo Bezerra. Rio de Janeiro: Forense-Universitária, 1981.

BANDEIRA, Manuel. Estrela da vida inteira: poesias reunidas. 8. ed. Rio de Janeiro: J. Olympio, 1980.

BATAILlE, Georges. O erotismo. Tradução de Antonio Carlos Viana. Porto Alegre: L\&PM, 1987.

BRAYNER, Sônia. O 'humour' bandeiriano ou as histórias de um sabonete. In: LOPEZ, Telê Porto Ancona. (Org.). Manuel Bandeira: verso e reverso. São Paulo: T. A. Queiroz, 1987. 
CÂMARA, Leônidas. A poesia de Manuel Bandeira: seu revestimento ideológico e formal. In: BRAYNER, Sônia (Org.). Manuel Bandeira. Rio de Janeiro: Civilização Brasileira; Brasília: Instituto Nacional do Livro, 1980.

FLORES JR., Wilson José. Fragmentos de uma subjetividade poética: três poemas de amor de Libertinagem, de Manuel Bandeira. Revista do GT de Teoria do Texto Poético, v. 4, 2007. Disponível em: http://www.textopoetico.org

IVO, Ledo. O preto no branco: exegese de um poema de Manuel Bandeira. Rio de Janeiro: São José, 1955.

OLIVEIRA, Franklin de. O medievalismo de Bandeira: a eterna elegia. In: BRAYNER, Sônia (Org.).Manuel Bandeira. Rio de Janeiro: Civilização Brasileira; Brasília: Instituto Nacional do Livro, 1980.

PERKOSKI, Norberto. A escritura erótica no sistema literário brasileiro. 1996. 312 f. Tese (Programa de Pós-Graduação em Letras) - Pontifícia Universidade Católica do Rio Grande do Sul, Porto Alegre, 1996.

ROSENBAUM, Yudith. Manuel Bandeira: uma poética da ausência. São Paulo: Universidade de São Paulo; Rio de Janeiro: Imago, 1993. 